of a ligature; but none of these projects were carried ont, because, in truth, the brothers themselves were not, except on rare occasions when extreme anger inflamed them, anxious to be disunited.

The structure of the connecting band being now known to $u s$, we are able, from an anatomical point of view, to form a better judgment as to what might have been the success of the proposed operation. On this knowledge taken alone we should incline to the opinion that those who were in favour of the operation were most correct. There was nothing anatomically which actually forbade the opera. tion. It would have been a dangerous operation, but certainly not more dangerous than ovariotomy, and when the men were in their heyday of youth it would have been justifiable. But there is what may be called the moral side of the question. We have seen how Eng actually died from emotional anxiety; and we doubt not that if the operation had been attempted in 1869 , one or both brothers would have succumbed, however skilful the surgery, from the mental shock to which they would have been subjected. It was well, therefore, that the advice of Syme, Fergusson, Warren, Mott, and Hollingsworth was followed, and that the brothers who had passed so long a life in their living bondage were allowed to proceed to the end of their course as they had lived from their birth.

The Siamese Twins have been for sixty years a curious phenomenon in the world. They have not lived, however, simply to be curious. The psychologist, the physiologist, the practical surgeon of the future, will learn from their history many a useful lesson; and as they all learn, they will, we are sure, remember with equal gratitude and admiration, the patience and skill of the two American anatomists from whose able report we have largely drawn in our present narrative.

\section{SLEEPING WITH OPEN WINDOWS.}

To the Editor of THE LANCET.

Sir,-I observe in your impression of to-day that Dr. MacCormac, of Belfast, has given as wide publicity as possible to what he evidently regards as a remarkable exhibition of ignorance on my part. He quotes from an account of one of my Royal Institution lectures, given in the Illustrated London News, that an "open window can seldom be endured in the night in this country."

It will, I trust, afford Dr. MacCormac much relief when I tell him that this statement was not made by me. In speaking of the ventilation of bedrooms, I said that although an open window is an excellent means of ventilation, there are many persons who cannot bear an open window in their bedrooms during the winter in this country (or words to that effect), but an aperture in the top or bottom of the door can always be tolerated. I endeavoured to show that there should always be at least such an aperture, of sufficient size, together with an open chimney. It is gratifying to learn that Dr. MacCormac and all his family can enjoy the practice of sleeping in rooms "betwixt the door and window widely open, the draught rushing backwards and forwards as it lists, with the temperature not much above freezing point." This statement may be regarded as sufficient proof of the robust constitutions possessed by Dr. MacCormac and the members of his family; but, notwithstanding Dr. MacCormac's excellent health, I would rather not recom mend the practice to anyone, and least of all should I dream of recommending such a procedure to those who have weak throats and chests. I doubt if sleeping with "open windows" "would cause an approximate if not entire cessation of the ravages of consumptive tubercular disease," as Dr. MacCormac so confidently maintains.

I am, Sir, yours, \&c.,

King”s College, 7th March, 1874.

W. RUTHERFORD.

\section{VALUE OF THE STAINING PROCESS IN THE HISTOLOGY OF THE MORBID BRAIN.}

\section{To the Editor of THE LANCET.}

SrR,-I have nuch pleasure in confirming the evidence of Dr. Major under the above heading in your last number.

I have in my cabinet several sections of brain and spinal cord from insane patients, which, in comparison with others from healthy animals, have not taken the staining at all well. Originally I considered this to be due to the postmortem change, which is necessarily acting for a longer time in human bodies subjected to an examination than in animals killed for the purpose of histological investigation.

To test the truth of this, however, I instituted a few experiments, which led me to the conclusion that the incapacity to stain was due to a pathological condition.

With regard to $\log$ wood staining, I may mention that, other things being equal, a bright day causes a much deeper stain than a dull one. This fact, which, I believe, has not been noticed before, is due to the lake-forming pro. perties of the dye.

With an expression of thanks to Dr. Major for having brought forward so important an item,

I remain, yours faithfully,

St. George's Hospital, Mareh 9, 1874. S. W. Moone.

\section{(Bbituatr.}

NEIT ARNOTT, M.D.

A PROMINENT figure in the gallery of "Self-Help" passed from among us on the 2nd inst. Dr. Neil Arnott died in London in his eighty-seventh year. In 1872 he sustained a fall by which his head was so severely injured that his faculties were irreparably impaired, and his friends had long ceased to hope for his recovery. He was buried beside his mother, his brother John, and his two sisters in the Dean Cemetery of Edinburgh.

Neil Arnott was born on the 15th of May, 1788, in the town of Arbroath, in the county of Angus. His father, who did not prosper much in business, took to farming and died early. His mother was a Maclean, and nearly connected with the surviving gentry of the clan. It was from her that Neil, James (still alive), and the other brothers and sisters inherited their remarkable gifts both of body and mind.

After successive migrations to Montrose, to the estate of the Roman Catholic College of Blairs, on Deeside, and to Aberdeen, Neil was put to the grammar school of that city - his energetic mother earning the means for so doing by opening a seminary for young ladies whom she taught in person. At school young Neil had Lord Byron as his com: panion, and as a boy was hardly less remarkable for his bright, inquisitive, unflagging intelligence. His proficiency in Latin was soon great, and enabled him to gain by competition a bursary in the Marischal College, which he entered in 1801 . In his third year he studied natural philosophy under Professor Copland-himself a proficient in the subject, which he made doubly fascinating by his clear style and beautiful experiments. It was Copland's lectures that really gave Neil Arnott his first distinct impulse in physical research, and prepared him admirably for the study of medicine, which he began at Aberdeen, and prosecuted in London in 1806. He was a pupil of Sir Everard Home's at St. George's, whose notice he attracted by his quickness of apprehension, and particularly by his rapid mastery of Sir Edward's new mode of treating stricture of the urethra. A patient of Sir Edward's, labouring under that malady, the captain of an East Indiaman, wished to have at sea with him some one who could treat him a la Sir Edward, and Arnott-incomplete as his educa. tion was-accepted the post of assistant-surgeon on board ship. This episode in his career was a favourite theme of his conversation in after-life. He imbibed knowledge from every one of his compagnons de voyage who could afford it, extending his notes on natural philosophy, studying and commenting on Adam Smith's "Wealth of Nations," and forming classes in French and Italian. One day the captain, in the excitement of a storm, let all his chronometers run down, and, on rewinding them, found they remained dead still. Arnott, having learned from Copland the mechanism of clockwork, soon set the chronometers agoing - to the delight of the captain and officers, who got him to deliver lectures on physics to them which formed the basis of his well-known treatise. Another feat was his performing on the captain the then novel operation of puncturing the bladder from the perineum. With all that he had a "larky" turn, and was fond of telling how he cir- 